\title{
GLACIER FLOW AND THE GROWTH OF THE GLACIER GRAIN
}

THE crystallographic results of the Jungfraujoch Research Party's investigations were published in the Proceedings of the Royal Society in August 1939. It has since occurred to me that insufficient attention was drawn to another factor affecting the movement and growth of the glacier grain, namely the possibility of pressure melting, followed by regelation. There are numerous air spaces between glacier grains at all stages until they approach the state of pure ice, and it seems natural that while two neighbouring grains (which are continually moving differentially to one another) are in contact, pressure melting, will take place, and that when the film of water reaches an air space it will refreeze. The effect will become less as the firn passes into ice owing to the decrease in the amount of air space and the increased interlocking of the grains, which makes their differential movement more difficult. Naturally, also, pressure melting would not take place at those points in the glacier which were appreciably below freezing point.

An interesting criticism of the findings in the above-mentioned paper was made to me by Professor Ahlmann. We stated that when the specific gravity of the firn exceeds about 0.82 it changes into ice. The transition point was fixed at the stage when the air spaces between the grains become sealed up and cease to be communicating. How then, Professor Ahlmann asks, could further water impregnate the ice at 0.82 to give it a specific gravity of 0.91 ?

Unfortunately the last stages of the transition of "early" ice to "pure" ice were not fully investigated owing to lack of time. I intend to come back to this part of the investigations later. Therefore what follows is only conjecture.

There is the possibility that under the influence of plastic deformation, air bubbles may wander and form bigger ones which are eliminated in crevasses, cracks or on the surface. Tyndall reported the emission of air with a loud hissing sound from cracks in the Mer de Glace.

There is also evidence that air bubbles become compressed. Wegener found that air bubbles in ice were under pressures of as much as ro atmospheres. But a more likely explanation arises from the possibility that ice at a specific gravity of 0.91 only occurs when it has become impregnated with water before the air channels become sealed up. There is no evidence that ice entirely free from air is found anywhere except at the surface or in crevasses. In other words, it is possible that if the firn is not fully impregnated with water before the air spaces cease to be communicating, it never becomes air-free until or unless it can discharge its air into the atmosphere at the surface or into crevasses. Clearly this is an interesting subject for further research.

G. Seligman

\section{THE RONDANE, NORWAY}

Two members of the Society, Dr. S. E. Hollingworth and Mr. W. Vaughan Lewis, joined Dr. K. M. Strøm's expedition to the Rondane Mountains of Central Norway in June 1946. The principal subjects of study were geomorphological problems associated with the glaciation of the area and the mode of disappearance of the last Pleistocene ice-sheets. The detailed work of Dr. Strøm and his collaborator, Hr. Tore Sund, have amply confirmed the earlier view of Dr. Carl M. Mannerfelt, based on studies in Sweden and Norway, that the ice in the mountain areas became "climatically dead" at an early stage in the waning of the Scandinavian ice-sheet. The snow line was well above the level of the surface of the ice when the latter stood at 1600 metres. A wonderfully complete series of marginal channels with kettle-holed ablation moraine, outwash and fluvioglacial deposits characterize later stages in the decay of the dead ice.

S. E. H. 